\title{
Factors Affecting Verbal Agitation in Dementia Patients Living in Nursing Homes, South Korea
}

\author{
Eun Kyung Kim, Heeok Park* \\ College of Nursing, Research Institute of Nursing Science, Keimyung University, Daegu, South Korea \\ Email: 208736@kmu.ac.kr, ^hopark@kmu.ac.kr
}

How to cite this paper: Kim, E.K. and Park, H. (2018) Factors Affecting Verbal Agitation in Dementia Patients Living in Nursing Homes, South Korea. Open Journal of Nursing, 8, 339-354. https://doi.org/10.4236/ojn.2018.86028

Received: March 23, 2018

Accepted: June 2, 2018

Published: June 5, 2018

Copyright $\odot 2018$ by authors and Scientific Research Publishing Inc. This work is licensed under the Creative Commons Attribution International License (CC BY 4.0).

http://creativecommons.org/licenses/by/4.0/

\begin{abstract}
The purpose of this study using secondary data analysis was to identify factors affecting verbal agitation in patients with dementia staying at nursing home. This study is a secondary analysis of an existing original quantitative data set $(n=193)$. A total of 166 subjects' data were included in this current study after 27 subjects' data were excluded from the original data because they did not appear verbal agitation. Multiple regression analyses identified hallucination $(\beta=0.27)$, total number of physiologic discomforts $(\beta=0.19)$ and pain $(\beta=$ $0.17)$ as significant predictors of verbal agitation and these factors explained $27.8 \%$ of the variance in the model. The findings of this study showed that hallucination, total number of physiologic discomforts and pain with dementia need to be considered when intervention programs to control verbal agitation in patients with dementia were developed.
\end{abstract}

\section{Keywords}

Dementia, Nursing Home, Psychomotor Agitation

\section{Introduction}

With advancements in modern medicine, the human lifespan has increased and accordingly, the world's elderly population is continuously increasing. Similarly, in Korea, the elderly population of age 65 or more has steadily increased and the country is predicted to become a super-aging society by 2026 , as the elderly population is estimated to comprise $20.8 \%$ of the entire population [1]. An increased elderly population is accompanied by an increased incidence of geriatric diseases, among which dementia is the most representative. Dementia is a chronic disease with a serious impact on the society. The incidence of dementia is reported to increase by twofold every 5 years after age 65 [2] and approximately $50 \%$ of the elderly aged 85 or more are affected by the condition [3]. 
According to a study conducted in Korea, the number of dementia patients is predicted to increase to a million by 2027 [4] and thus, it has been forecasted that the costs of dementia treatment and management, and consequent socioeconomic burdens will also increase.

Symptoms of dementia include behavioral problems, as well as impairments in memory and cognitive function [5]. Of the behavioral problems of dementia patients, agitation is manifest in most patients [6]. Different researchers define agitation differently, but the most commonly used definition is "inappropriate verbal, vocal, and motor activity that is not based on a clear necessity or confusion." [7] Agitation can be grouped into aggressive/non-aggressive behaviors, or physical/verbal and vocal behaviors [8]. Of those, inappropriate verbal agitation refers to verbally non-aggressive behavior such as repetitive questions, complaining and attention-seeking behaviors, and verbally aggressive behavior such as cursing and screaming.

It has been reported that the incidence of verbal agitation is higher than physical agitation in dementia patients [8] [9] [10]. Studies have shown that verbal agitation like screaming induces sleep disturbance and threat to caregivers and that such verbally non-aggressive behavior as repetitive sentences and questions, which occur most frequently, is the most difficult for caregivers to deal with [11]. Furthermore, caregivers are psychologically hurt by dementia patients' cursing. In sum, verbal agitation is burdensome to families and caregivers, and such burdens may induce them to send dementia patients to hospitals and nursing homes, increasing personal-social costs of care [12]. Accordingly, research is needed to identify the factors affecting verbal agitation in dementia patients.

A review of previous studies conducted outside of Korea to identify factors influencing verbal agitation of dementia patients showed the following results. Cohen-Mansfield et al. [13] reported that verbal agitation is influenced by severe pain. Cohen-Mansfield and Marx [14] found a higher incidence of verbal agitation in women, but Schreiner [9] did not find a gender difference. Cohen-Mansfield and Libin [15] reported that age, depression, cognitive impairment, activities of daily living (ADL), and impaired social functioning affected verbal agitation. Also, discomfort was reported by Pelletier and Landreville [16], and the severity of dementia by Zuidema et al. [17], as a factor influencing verbal agitation.

According to a review of studies conducted in Korea, Kang [18] investigated the factors of disturbing behaviors in older adults with dementia staying at home using Algase et al.'s [19] "disturbing behaviors" tool; the study differed from current study in that this study was conducted at nursing homes. A study by Kang [18] showed that characteristics including gender, relationship with spouse, and agreeableness were significant factors that were associated with verbally aggressive behavior to be one of the disturbing behaviors. However, the number of domestic studies on factors influencing verbal agitation in dementia patients is very small. 
No independent study has been conducted with focus on verbal agitation, and moreover, different studies have found different influential factors. Therefore, research should be replicated. Most of the previous studies investigated factors influencing overall agitation, limiting the understanding of influential factors by the type of agitation. A systematic study should be conducted to examine the characteristics of dementia patients and investigate their relationship with verbal agitation.

Accordingly, this current study was conducted to investigate factors affecting verbal agitation in dementia patients living in nursing homes in Korea and suggest appropriate ways to prevent and manage verbal agitation. The framework of the research was based on the background and proximal factors of the need-driven behavior model proposed by Algase et al. [19] to explain the causes of agitation in dementia patients. The purpose of the present study was to use the data of by Gang et al.'s [10] study to 1) examine the extent of agitation and identify the background and proximal factors of agitation in the subjects; 2) explore any differences in verbal agitation according to the background and proximal factors; 3 ) investigate the relationship of background factors, proximal factors, and verbal agitation; and 4) identify the factors affecting verbal agitation.

\section{Methods}

\subsection{Study Design}

This study involved a secondary analysis of an existing dataset, with the re-use of quantitative data derived from pre-existing research studies [10].

\subsection{Data Sets}

The original quantitative dataset $(\mathrm{n}=193)$ was acquired from 4 nursing homes in South Korea for a study that investigated the agitation factors in patients with dementia from December 1 to 28, 2015. However, 27 subjects' data were excluded for this current study because they did not show verbal agitation. Finally, a total of 166 subjects' data were included in this current study.

\subsection{Research Instruments}

\subsubsection{Verbal Agitation}

CMAI, a tool developed by Cohen-Mansfieid and Billig [7], was used to measure verbal agitation. To translate the instrument into Korean, the Korean version of CMAI published by Suh [20] was referred to and some of the items in that version were used. The tool to assess agitation in dementia patients was originally developed to consist of a total of 29 items across 4 areas, i.e., 12 items regarding physically aggressive behavior, 9 items regarding physically non-aggressive behavior, 4 items regarding verbally aggressive behavior, and 4 items regarding verbally non-aggressive behavior [7]. Of those, items regarding verbal agitation were used in the present study, i.e., 4 items each for verbally aggressive and verbally non-aggressive behavior. Verbally aggressive behavior includes screaming, 
cursing, making strange noises and verbal sexual advances, and verbally non-aggressive behavior attention-seeking behaviors, complaining, negativism and repetitive sentences or questions

CMAI items are measured via a 7-point Likert scale, where 1 point is assigned to "not at all" and 7 points to "several times an hour." The higher the score, the more frequent the aggressive behavior. Cronbach's $\alpha$ was 0.92 at the time when the tool was developed [7], and 0.94 in the present study. The Cronbach's $\alpha$ of only the items regarding verbal agitation was 0.86 .

\subsubsection{Background Factors of Agitation}

1) Cognitive function

Cognitive function was measured with K-MMSE (Korean Mini-Mental State Examination) translated by Kang et al. [21] from the MMSE developed by Folstein et al. [22]. Scores of the instrument range from 0 to 30, and the higher the total score, the higher the cognitive function. A score between 20 and 23 is classified as mild, a score between 10 and 19 as moderate, and a score less than 10 as severe. The test-retest reliability Cronbach's $\alpha$ was 0.89 at the time when the tool was developed and 0.83 in the present study.

2) Communication

In order to assess dementia patients' communication ability, the Holden Communication Scale developed by Holden and Sinebruchow [23] and translated by Gang [24] was used. The scale was specifically developed to measure communication of dementia patients, and the items are rated by an observer. There are a total of 12 items, each of which is measured on a 5-point scale and scored between 0 and 4 , and the lower the total score, the higher the communication. The Cronbach's $\alpha$ was 0.91 in Gang's study and 0.94 in the present study.

3) Activities of Daily Living (ADL)

ADL was assessedwith K-ADL (Korea Activity of Daily Living Scale) developed by Won et al. [25]. The tool comprises a total of 7 items, and each item is rated as complete independence (1 point), partial independence ( 2 points), or complete dependence ( 3 points). The higher the score, the lower the ADL. Cronbach's $\alpha$ was 0.95 in the study by Won et al. [25] and 0.93 in the present study.

\subsubsection{Proximal Factors of Agitation}

1) Pain

Pain was evaluated with DS-DAT (Discomfort scale-Dementia of the Alzheimer's Type) developed by Hurley et al. [26] and translated by Kim [27]. The scale was developed to assess pain in Alzheimer's patients and the items are rated by an observer. It consists of a total of 9 items, and each item is measured via a 4-point scale, scored 0 for "no pain at all" through 3 for "severe pain." The higher the score, the more severe the pain. Cronbach's $\alpha$ was 0.76 in Kim's study and 0.61 in the present study.

2) Depression 
Depression was evaluated by using the Korean version of the CSDD (the Cornell Scale for Depression in Dementia) originally developed by Alexopouls et al. [28] and translated by Kim et al. [29]. This scale is rated by an observer for depression in dementia patients, consisting of a total of 19 items. The CSDD is divided into five subscales: mood-related, behavioral disturbance, physical signs, cyclic function, and ideational disturbance. Each item is assigned with A for "symptoms not possible to evaluate", 0 point for "absent", 1 point for "mild", and 2 points for "severe". The total score ranges from 0 to 38; a higher score denotes greater levels of depression. Cronbach's $\alpha$ in the Korean version of the CSDD was .84 in the original study, and 0.87 in the present study.

3) Neuropsychiatric disturbance

Four items regarding delusion ( 2 items) and hallucination (2 items) of the NPI (Neuropsychiatric Inventory) were used. The inventory was developed by Cummings et al. [30] to assess behavioral and psychological symptoms of dementia, and translated into Korean by Choi et al. [31]. Each item is scored by multiplying frequency (rated on a 4-point scale) and severity (rated on a 3-point scale), and the higher the score the more severe the corresponding symptom. Cronbach's $\alpha$ was .85 in the study by Choi [31] et al., and 0.91 in the present study.

\subsubsection{Physical and Psychosocial Environmental Features}

The tool developed by Kang [18] to evaluate the features of physical and psychosocial environments of dementia patients was used. This instrument consists of a total of 19 items in two areas, physical and psychosocial environments. Physical environment refers to the space in which the patient spends most of the time (patient's room), and the environmental features are assessed with 9 items, including temperature, air circulation, and light in the room. Regarding psychosocial environmental features, the attitudes of the family and the main caregivers toward the patient and the like are asked across 10 items. Each of the 19 items is measured on a 5-point scale, with 1 point assigned to "highly unlikely" and 5 points to "highly likely", and the higher the score, the better the environmental condition. Cronbach's $\alpha$ values were 0.82 and 0.81 for the physical and psychosocial environments, respectively, at the time when the tool was developed, and 0.82 and 0.80 , respectively for the physical and psychosocial environments, in the present study.

Ethical consideration

The proposal of this current study was submitted to the research ethics committee and the requirement for informed consent was waived due to the retrospective nature of the study.

\subsection{Data Analysis}

The data were analyzed using SPSS/WIN19 (IBM Corp., Armonk, NY, USA).

1) Descriptive statistics were computed to examine the extent of verbal agitation and the background and proximal factors. 
2) T-test, ANOVA, Scheffe test, and Dunnet T3 were conducted to investigate differences in verbal agitation according to the background and proximal factors.

3) Pearson's correlation coefficients were computed for the correlations between the background and proximal factors and verbal agitation.

4) Multiple regression was performed to identify the factors affecting verbal agitation.

\section{Results}

\subsection{Subjects' Characteristics}

Subjects' characteristics are presented in Table 1. The mean age was $80.74 \pm$ 8.49 , and 60 - 80 years was the largest age group 74 (44.6\%). Females comprised 118 (71.1\%) of the sample, 86 (51.8\%) had no formal education, and 119 (71.7\%) did not have a spouse. Regarding dementia-related characteristics, 129 (77.7\%) had Alzheimer type dementia. Seventy one (42.8\%) subjects suffered from dementia for 1 to 2 years, and 92 (55.4\%) had no or one disease other than dementia. The mean score of cognitive function was $11.68 \pm 5.59$, suggesting that overall, dementia was severe. The mean score of communication was $25.87 \pm 11.21$. In all, $72.3 \%$ of participants were treated with Medication regarding to dementia, and $51.8 \%$ were treated with antipsychotic drugs. Regarding health status, the mean ADL score was $15.38 \pm 4.00$, and higher proportions of subjects had no hearing loss $134(80.7 \%)$ and vision problem 148 (89.2\%) compared to those with such problems.

Regarding physiological needs, 84 (50.6\%) had physiological discomfort, and the mean pain score was $9.59 \pm 3.67$. The mean hours of sleep per day were 7.01 \pm 1.77 , and sleep quality was medium in 91 (54.8\%). Regarding psychosocial needs, the mean depression score was $12.81 \pm 8.58$ and scores for delusion and hallucination were low, with mean scores of $1.92 \pm 3.21$ and $1.65 \pm 2.96$, respectively. Mean scores of physical and psychosocial environments were also slightly low (35.54 \pm 4.62 and $32.46 \pm 6.01$, respectively). 153 (92.2\%) were visited by family at least once in the last month, 110 (66.3\%) were visited by family 3 times or fewer, and 66 (39.8\%) held negative pre-illness family relationships.

Mean score of verbal agitation was $2.20 \pm 1.14$. By subdomain, the mean score was $1.86 \pm 1.07$ for verbally aggressive behavior and $2.54 \pm 1.38$ for verbally non-aggressive behavior.

\subsection{Verbal Agitation According to Subjects' Characteristics}

Verbal agitation according to subjects' characteristics is shown in Table 2. Sleep quality showed differences in verbal agitation $(\mathrm{F}=3.50, p=0.032)$, but the post-hoc test result was not significant.

Subdomains of verbal agitation were examined by subjects' characteristic. Verbally aggressive behavior was different depending on the presence of a spouse $(\mathrm{t}=2.40, p=0.019)$ and dementia type $(\mathrm{t}=4.07, p=0.019)$, while 
Table 1. Subjects' characteristics $(\mathrm{N}=166)$.

\begin{tabular}{|c|c|c|c|c|}
\hline Classification & Variables & Categories & $\mathrm{n}(\%)$ or $\mathrm{M} \pm \mathrm{SD}$ & Possible range \\
\hline \multirow[t]{11}{*}{ Demographic characteristics } & Age(year) & & $80.74 \pm 8.49$ & \\
\hline & & $60-80$ & $74(44.6)$ & \\
\hline & & $81-90$ & $70(42.2)$ & \\
\hline & & 91 & $22(13.2)$ & \\
\hline & Gender & Male & $48(28.9)$ & \\
\hline & & Female & $118(71.1)$ & \\
\hline & Education & None & $86(51.8)$ & \\
\hline & & Elementary & $49(29.5)$ & \\
\hline & & $\geq 9$ Middle & $31(18.7)$ & \\
\hline & Spouse & Yes & $47(28.3)$ & \\
\hline & & No & $119(71.7)$ & \\
\hline \multirow{17}{*}{$\begin{array}{c}\text { Dementia-related } \\
\text { characteristics }\end{array}$} & Dementia type & Alzheimer's dementia & $129(77.7)$ & \\
\hline & & Vascular dementia & $30(18.1)$ & \\
\hline & & Others & $7(4.2)$ & \\
\hline & Total period of being diagnosed & & $3.43 \pm 2.59$ & \\
\hline & with dementia (year) & $1-2$ & $71(42.8)$ & \\
\hline & & $3-5$ & 69 (41.6) & \\
\hline & & $\geq 6$ & $26(15.6)$ & \\
\hline & Total number of other & & $1.56 \pm 0.89$ & \\
\hline & diagnosed diseases & $0-1$ & $92(55.4)$ & \\
\hline & & $\geq 2$ & $74(44.6)$ & \\
\hline & cognitive function & & $11.68 \pm 5.59$ & $0-23$ \\
\hline & Communication & & $25.8 \pm 11.21$ & $0-48$ \\
\hline & Medication $\dagger$ & & & \\
\hline & Dementia related & Yes & $120(72.3)$ & \\
\hline & & No & $46(27.7)$ & \\
\hline & Antipsychotic & Yes & $86(51.8)$ & \\
\hline & & No & $80(48.2)$ & \\
\hline \multirow[t]{5}{*}{ Health status } & $\mathrm{ADL}$ & & $15.38 \pm 4.00$ & $7-21$ \\
\hline & hearing loss & Yes & $32(19.3)$ & \\
\hline & & No & $134(80.7)$ & \\
\hline & vision problem & Yes & $18(10.8)$ & \\
\hline & & No & $148(89.2)$ & \\
\hline \multirow[t]{8}{*}{ Physiological need states } & Total number of & & $0.91 \pm 1.16$ & \\
\hline & physiologic discomforts & Yes & $82(49.4)$ & \\
\hline & & No & $84(50.6)$ & \\
\hline & Pain & & $9.59 \pm 3.67$ & $0-27$ \\
\hline & Hours of sleep per day & & $7.01 \pm 1.77$ & \\
\hline & Quality of sleep & High & $38(22.9)$ & \\
\hline & & Meddle & $91(54.8)$ & \\
\hline & & Low & $37(22.3)$ & \\
\hline \multirow[t]{2}{*}{ Psychological need states } & Depression Psychotic symptom & & $12.81 \pm 8.58$ & $0-38$ \\
\hline & & Delusion & $1.92 \pm 3.21$ & \\
\hline
\end{tabular}




\section{Continued}

\begin{tabular}{|c|c|c|c|}
\hline & Hallucination & $1.65 \pm 2.96$ & \\
\hline & Total & $3.57 \pm 5.66$ & \\
\hline Physical environment & & $35.54 \pm 4.62$ & $9-45$ \\
\hline & & $32.46 \pm 6.01$ & \\
\hline \multirow{8}{*}{ Psychosocial environment } & Yes & $153(92.2)$ & \\
\hline & No & $13(7.8)$ & \\
\hline & & $4.02 \pm 6.01$ & \\
\hline & $0-3$ & $110(66.3)$ & \\
\hline & $\geq 4$ & $56(33.7)$ & \\
\hline & Good & $62(37.3)$ & \\
\hline & Fair & $12(7.2)$ & \\
\hline & Bad & $66(39.8)$ & \\
\hline & Not Known & $26(15.7)$ & \\
\hline \multicolumn{2}{|c|}{ Verbally aggressive behavior } & $1.86 \pm 1.07$ & $1-7$ \\
\hline \multirow{2}{*}{ Verbally Agitation } & Verbally non-aggressive behavior & $2.54 \pm 1.38$ & $1-7$ \\
\hline & Total Verbally Agitation & $2.20 \pm 1.14$ & $1-7$ \\
\hline
\end{tabular}

$\mathrm{ADL}=$ Activity of daily living; $\uparrow$ Duplicated response.

Table 2. Verbal Agitation according to Subjects' Characteristics $(\mathrm{N}=166)$.

\begin{tabular}{|c|c|c|c|c|c|c|c|}
\hline \multirow{3}{*}{ Variables } & \multirow{3}{*}{ categories } & \multicolumn{6}{|c|}{ Verbally agitation } \\
\hline & & \multicolumn{2}{|c|}{ Total } & \multicolumn{2}{|c|}{ Verbally aggressive } & \multicolumn{2}{|c|}{ Verbally non-aggressive } \\
\hline & & $\mathrm{M} \pm \mathrm{SD}$ & tor $\mathrm{F}(p)$ & $\mathrm{M} \pm \mathrm{SD}$ & t or $\mathrm{F}(p)$ & $\mathrm{M} \pm \mathrm{SD}$ & tor $\mathrm{F}(p)$ \\
\hline \multirow[t]{3}{*}{ Age(year) } & $60-80$ & $2.23 \pm 1.09$ & 0.32 & $1.86 \pm 0.98$ & 0.38 & $2.59 \pm 1.36$ & 0.23 \\
\hline & $81-90$ & $2.13 \pm 1.21$ & $(0.723)$ & $1.80 \pm 1.15$ & $(0.683)$ & $2.46 \pm 1.43$ & $(0.789)$ \\
\hline & $\geq 91$ & $2.35 \pm 1.10$ & & $2.03 \pm 1.11$ & & $2.67 \pm 1.31$ & \\
\hline \multirow[t]{2}{*}{ Gender } & Male & $2.13 \pm 0.94$ & -0.54 & $1.87 \pm 0.96$ & 0.10 & $2.38 \pm 1.07$ & -1.11 \\
\hline & Female & $2.23 \pm 1.21$ & $(0.587)$ & $1.85 \pm 1.12$ & $(0.918)$ & $2.61 \pm 1.48$ & $(0.267)$ \\
\hline \multirow[t]{3}{*}{ Education } & None & $2.24 \pm 1.15$ & 0.10 & $1.88 \pm 1.08$ & 0.09 & $2.61 \pm 1.37$ & 0.20 \\
\hline & ES & $2.16 \pm 1.20$ & $(0.896)$ & $1.80 \pm 1.17$ & $(0.911)$ & $2.51 \pm 1.42$ & $(0.817)$ \\
\hline & $\geq \mathrm{MS}$ & $2.16 \pm 1.03$ & & $1.89 \pm 0.91$ & & $2.43 \pm 1.36$ & \\
\hline \multirow[t]{2}{*}{ Spouse } & Yes & $2.51 \pm 1.40$ & 1.92 & $2.21 \pm 1.32$ & 2.40 & $2.84 \pm 1.63$ & 1.73 \\
\hline & No & $2.08 \pm 1.00$ & $(0.059)$ & $1.71 \pm 0.92$ & $(0.019)$ & $2.43 \pm 1.25$ & $(0.089)$ \\
\hline Dementia & $\mathrm{AD}$ & $2.12 \pm 1.04$ & 2.11 & $1.73 \pm 0.94$ & 4.07 & $2.50 \pm 1.28$ & 1.76 \\
\hline \multirow[t]{2}{*}{ type } & VD & $2.59 \pm 1.48$ & $(0.125)$ & $2.28 \pm 1.45$ & $(0.019)$ & $2.90 \pm 1.75$ & $(0.175)$ \\
\hline & Others & $2.14 \pm 1.05$ & & $2.35 \pm 1.02$ & & $1.92 \pm 1.17$ & \\
\hline \multirow[t]{3}{*}{ Total } & $1-2$ & $2.32 \pm 1.30$ & 1.38 & $1.94 \pm 1.20$ & 2.33 & $2.71 \pm 1.53$ & 0.923 \\
\hline & $3-5$ & $2.03 \pm 0.89$ & $(0.254)$ & $1.66 \pm 0.81$ & $(0.100)$ & $2.39 \pm 1.16$ & $(0.399)$ \\
\hline & $\geq 6$ & $2.33 \pm 1.23$ & & $2.15 \pm 1.23$ & & $2.51 \pm 1.45$ & \\
\hline \multirow[t]{2}{*}{ Total 2} & $0-1$ & $2.13 \pm 1.01$ & -0.95 & $1.79 \pm 0.98$ & -0.87 & $2.46 \pm 1.24$ & -0.91 \\
\hline & $\geq 2$ & $2.30 \pm 1.28$ & $(0.340)$ & $1.94 \pm 1.18$ & $(0.385)$ & $2.65 \pm 1.53$ & $(0.363)$ \\
\hline Dementia related & Yes & $2.25 \pm 1.14$ & 0.86 & $1.87 \pm 1.05$ & 0.30 & $2.62 \pm 1.38$ & 1.19 \\
\hline medication & No & $2.08 \pm 1.14$ & $(0.388)$ & $1.82 \pm 1.14$ & $(0.763)$ & $2.34 \pm 1.36$ & $(0.223)$ \\
\hline Antipsychotic & Yes & $2.28 \pm 1.18$ & 0.84 & $1.92 \pm 1.13$ & 0.81 & $2.62 \pm 1.43$ & 0.75 \\
\hline
\end{tabular}




\begin{tabular}{|c|c|c|c|c|c|c|c|}
\hline \multicolumn{8}{|l|}{ Continued } \\
\hline medication & No & $2.13 \pm 1.09$ & $(0.402)$ & $1.79 \pm 1.01$ & $(0.415)$ & $2.46 \pm 1.33$ & $(0.451)$ \\
\hline Health status & Yes & $2.48 \pm 1.33$ & 1.51 & $2.10 \pm 1.26$ & 1.27 & $2.85 \pm 1.57$ & 1.37 \\
\hline hearing loss & No & $2.14 \pm 1.08$ & $(0.131)$ & $1.80 \pm 1.02$ & $(0.209)$ & $2.47 \pm 1.32$ & $(0.170)$ \\
\hline \multirow[t]{2}{*}{ vision problem } & Yes & $2.73 \pm 1.59$ & 1.51 & $2.50 \pm 1.44$ & 2.04 & $2.95 \pm 1.91$ & 0.98 \\
\hline & No & $2.14 \pm 1.06$ & $(0.146)$ & $1.78 \pm 1.00$ & $(0.055)$ & $2.50 \pm 1.30$ & $(0.336)$ \\
\hline \multicolumn{8}{|c|}{ Physiological need states } \\
\hline \multirow[t]{3}{*}{ Quality of sleep } & High & $2.17 \pm 1.08$ & 3.50 & $1.80 \pm 0.94$ & 2.69 & $2.53 \pm 1.45$ & 3.33 \\
\hline & Middle & $2.05 \pm 0.98$ & $(0.032)$ & $1.74 \pm 0.94$ & $(0.071)$ & $2.35 \pm 1.18$ & $(0.038)$ \\
\hline & Low & $2.63 \pm 1.45$ & & $2.21 \pm 1.41$ & & $3.04 \pm 1.64$ & \\
\hline \multicolumn{8}{|c|}{ Psychosocial environment } \\
\hline \multirow{2}{*}{$\begin{array}{l}\text { Family visiting } \\
\text { (per month) }\end{array}$} & Yes & $2.21 \pm 1.16$ & 0.07 & $1.84 \pm 1.09$ & -0.55 & $2.56 \pm 1.40$ & 0.58 \\
\hline & No & $2.18 \pm 0.91$ & $(0.941)$ & $2.01 \pm 0.80$ & $(0.583)$ & $2.34 \pm 1.10$ & $(0.582)$ \\
\hline \multirow{2}{*}{$\begin{array}{l}\text { Total number of } \\
\text { visits(per month) }\end{array}$} & $0-3$ & $2.28 \pm 1.17$ & 1.26 & $1.94 \pm 1.10$ & 1.41 & $2.62 \pm 1.41$ & 0.98 \\
\hline & $\geq 4$ & $2.05 \pm 1.07$ & $(0.209)$ & $1.69 \pm 0.99$ & $(0.159)$ & $2.40 \pm 1.31$ & $(0.327)$ \\
\hline \multirow{4}{*}{$\begin{array}{l}\text { Pre-illness family } \\
\text { relationship }\end{array}$} & Good & $2.22 \pm 1.26$ & 0.21 & $1.83 \pm 1.13$ & 0.23 & $2.61 \pm 1.55$ & 0.29 \\
\hline & Fair & $1.96 \pm 0.71$ & $(0.886)$ & $1.70 \pm 0.54$ & $(0.869)$ & $2.20 \pm 1.02$ & $(0.833)$ \\
\hline & $\mathrm{Bad}$ & $2.21 \pm 1.02$ & & $1.86 \pm 0.99$ & & $2.55 \pm 1.25$ & \\
\hline & Not Known & $2.27 \pm 1.31$ & & $2.00 \pm 1.30$ & & $2.53 \pm 1.44$ & \\
\hline
\end{tabular}

ES = Elementary school, MS = Middle school; $\mathrm{AD}=$ Alzheimer's disease; $\mathrm{VD}=$ Vascular dementia; Total $1=$ Total period of being diagnosed with dementia (years); Total 2 = Total number of other diagnosed diseases.

verbally non-aggressive behavior was different depending on sleep quality $(\mathrm{F}=$ $3.33, p=0.038)$.

\subsection{Correlations between Subjects' Characteristics and Verbal Agitation}

The correlations of subjects' characteristics and verbal agitation are presented in Table 3. Overall agitation showed significant positive correlations with physiological discomfort $(\mathrm{r}=0.31, p<0.001)$, pain $(\mathrm{r}=0.32, p<0.001)$, depression $(\mathrm{r}=$ $0.24, p=0.002)$, delusion $(\mathrm{r}=0.42, p<0.001)$, and hallucination $(\mathrm{r}=0.43, p=<$ $0.001)$. Overall agitation was negatively correlated with cognitive function $(r=$ $-0.16, p=0.029$ ).

Each subdomain of verbal agitation was as follows. First, verbally aggressive behavior had significant positive correlations with communication $(\mathrm{r}=0.16, p=$ 0.031), physiological discomfort $(\mathrm{r}=0.21, p=0.006)$, pain $(\mathrm{r}=0.26, p<0.001)$, depression $(\mathrm{r}=0.30, p<0.001)$, delusion $(\mathrm{r}=0.41, p<0.001)$, and hallucination $(\mathrm{r}=0.43, p<0.001)$, while it had a significant negative correlation with cognitive function $(\mathrm{r}=-0.22, p=0.004)$. Next, verbally non-aggressive behavior had significant positive correlations with physiological discomfort $(\mathrm{r}=0.35, p<0.001)$, 
Table 3. Correlation between Subjects' Characteristics and Verbally Agitation $(\mathrm{N}=166)$.

\begin{tabular}{lccc}
\hline & \multicolumn{3}{c}{ Verbally agitation } \\
\cline { 2 - 4 } Variables & Total & $\begin{array}{c}\text { Verbally } \\
\text { aggressive }\end{array}$ & $\begin{array}{c}\text { Verbally } \\
\text { non-aggressive }\end{array}$ \\
\cline { 2 - 4 } & $\mathrm{r}(p)$ & $\mathrm{r}(p)$ & $\mathrm{r}(p)$ \\
\hline Cognitive ability & $-0.16(0.029)$ & $-0.22(0.004)$ & $-0.10(0.164)$ \\
Communication skill & $0.09(0.230)$ & $0.16(0.031)$ & $0.02(0.747)$ \\
ADL & $0.11(0.152)$ & $0.15(0.051)$ & $0.06(0.394)$ \\
Total number of & $0.31(<0.001)$ & $0.21(0.006)$ & $0.35(<0.001)$ \\
physiologic discomforts & $0.32(<0.001)$ & $0.26(<0.001)$ & $0.32(<0.001)$ \\
Pain & $-0.10(0.162)$ & $-0.11(0.157)$ & $-0.09(0.226)$ \\
Hours of sleep per day & $0.24(0.002)$ & $0.30(<0.001)$ & $0.16(0.034)$ \\
Depression & $0.42(<0.001)$ & $0.41(<0.001)$ & $0.37(<0.001)$ \\
Delusion & $0.43(<0.001)$ & $0.43(<0.001)$ & $0.39(<0.001)$ \\
Hallucination & $-0.04(0.556)$ & $0.04(0.584)$ & $-0.11(0.160)$ \\
Physical environment & $0.02(0.800)$ & $0.00(0.944)$ & $0.02(0.713)$ \\
Psychosocial & & &
\end{tabular}

pain $(\mathrm{r}=0.32, p=<0.001)$, depression $(\mathrm{r}=0.16, p=0.034)$, delusion $(\mathrm{r}=0.37, p$ $<0.001)$, and hallucination $(\mathrm{r}=0.39, p<0.001)$.

\subsection{Factors Affecting Verbal Agitation}

The factors influencing verbal agitation are listed in Table 4. To investigate factors affecting verbal agitation, multiple regression analysis was performed with verbal agitation as the dependent variable, and cognitive function, physiological discomfort, pain, depression, delusion, and hallucination as independent variables. Tolerance among the independent variables ranged from 0.505 to 0.870 , all under the threshold of 1.00, and no values of variance inflation factor (VIF; 1.149 - 1.979) exceeded the threshold of 10 , indicating that multicollinearity was not an issue. To test for the independence of residuals, the Durbin-Watson statistic was computed, and the value was 1.910 , a value relatively close to 2 , thus suggesting no autocorrelation in the residuals.

The multiple regression analysis results showed that hallucination $(\beta=0.27, p$ $=0.004)$, physiological discomfort $(\beta=0.19, p=0.007)$, and pain $(\beta=0.17, p=$ $0.020)$ influenced verbal agitation, in this order. These variables in combination explained $27.8 \%$ of the variance of verbal agitation.

\section{Discussion}

The present study aimed to identify the factors affecting verbal agitation in dementia patients living in nursing homes. To achieve the goal, the study was conducted based on the background and proximal factors of the need-driven behavior model ${ }^{19}$ developed to explain the causes of agitation in dementia patients. 
Table 4. Factors affecting verbal agitation $(\mathrm{N}=166)$.

\begin{tabular}{lllll}
\hline Variables & $\mathrm{B}$ & $\beta$ & $\mathrm{t}$ & $p$ \\
\hline cognitive ability & 0.00 & 0.01 & 0.23 & 0.818 \\
Total number of physiologic discomforts & 0.19 & 0.19 & 2.71 & 0.007 \\
Pain & 0.05 & 0.17 & 2.34 & 0.020 \\
Depression & 0.00 & 0.04 & 0.50 & 0.614 \\
Delusion & 0.05 & 0.14 & 1.56 & 0.121 \\
Hallucination & 0.10 & 0.27 & 2.95 & 0.004 \\
\hline
\end{tabular}

Adj. $\mathrm{R}^{2}=0.278, \mathrm{~F}=11.61, P<0.001$.

Previous studies [10] [32] [33] which investigated factors influencing physical and verbal agitation, as defined by Cohen-Mansfield [8], have identified cognitive function, dementia type and duration, drugs, ADL, pain, depression, hallucination, and delusion as influential factors. Physical and verbal agitation was also found to be affected by different factors.

Regarding physical agitation, Cohen-Mansfield et al. [34] showed cognitive function decreases with increasing physical non-aggressive behavior. Gang et al. [10] did not find the effect of cognitive function on physical agitation, but found that the duration of dementia, visual acuity, sleep quality, and physiological discomfort influenced physical agitation. On the other hand, with respect to verbal agitation, previous studies have identified severe pain [13], discomfort [16], and hallucination [35] as the influential factors, suggesting that verbal agitation is affected by sensory perceptual factors. The present study finding that hallucination, physiological discomfort, and pain affected verbal agitation is in line with these previous findings, in that they are health issues related to sensory perception.

The present study found that hallucination is the most powerful factor influencing verbal agitation, similarly to the finding reported in Leonard et al. [35] that hallucination was significantly associated with verbal agitation in dementia patients living in nursing homes. Delusion and hallucination are common symptoms of dementia [36] [37]. Dementia patients experiencing delusion or hallucination may display verbal agitation e.g., talking with a person not present, calling a name, or claiming that something is under the bed. Such behavior can continue into the night, disturbing the sleep of others as well as themselves [11]. The importance of physical environments like delusion and hallucinations as factors affecting agitation have been stressed only since 2010 [36] [38], so not much research has been conducted on hallucination as a factor affecting agitation, and particularly verbal agitation. Even when the effect of hallucination was investigated, inconsistent results were reported across studies. It is speculated that the findings are inconsistent because many dementia patients are treated with antipsychotics to alleviate the symptoms of delusion and hallucination, and antipsychotic dosages prescribed to them are diverse. Currently, pharmacological therapy is the main treatment to control hallucination in dementia patients, 
but it can cause side effects such as fall and fainting [38]. To manage hallucination that causes verbal agitation, a protocol that is practical and convenient to use should be developed and its effect examined.

In addition to hallucination, increased physical discomfort such as constipation, diarrhea, and thirst significantly influenced verbal agitation. In a study conducted by Pelletier and Landreville too [16], discomfort was found to affect verbal agitation. It is difficult for dementia patients to actively communicate physiological discomfort. Accordingly, agitation can be understood as a way to draw the caregiver's attention through behaviors like complaining and screaming [16]. To reduce verbal agitation due to physiological discomfort, patients' verbal and non-verbal expressions should be accurately comprehended, and to do so, nurses' clinical experience is critical [39]. Hence, caregivers should be academically trained so that they can recognize verbal expressions of dementia patients and try to understand the reasons.

Lastly, pain was found to influence verbal agitation, a finding consistent with the results reported in Cohen-Mansfield, et al. [13]. Due to aging, dementia patients are likely to have underlying disease causing pain such as angina pectoris and arthritis. It is not that they do not have pain, but only that they cannot convey that they have pain because of cognitive impairment, and their pain is related to cognitive and non-cognitive symptoms. Accordingly, pain management is an important treatment in nursing of the elderly with dementia [40]. However, in a study [41], pain was confirmed by medical staff only in $43 \%$ of patients able to communicate and $17 \%$ of those unable to communicate. Pain is a subjective experience, and can be accurately assessed if the patient verbally describes it [42]. It is difficult to manage pain in dementia patients who cannot communicate. Especially, the passive attitude of medical staff toward pain management in dementia patients and the bias toward pharmacological intervention are main causes of dementia patients' low quality of life [41]. Pain perception is still preserved in patients with dementia, though they may be unable to communicate it due to impaired cognition, and so they try to communicate that they feel pain through verbal and non-verbal methods [42]. Verbal agitation like repetitive vocalization can be a clue [41] and therefore, it should not be overlooked and should be monitored before developing into more excessive behavior.

The original study by Gang et al.'s [10] showed that the agitation factors were hallucination, delirium, pain, and the total period of being diagnosed with dementia. The findings of the current study showed that verbal agitation factors included hallucination, discomfort, and pain. Based on the results of the two studies, hallucination and pain were two common factors to cause agitation and verbal agitation. In addition, physical discomfort was the only factor to induce verbal agitation in patients with dementia staying at nursing homes. Because verbal agitation is inclined to regularly and continuously occur and is not understandable to caregivers [11], the interventions to reduce verbal agitation need to be considered with priorities at nursing homes. It is especially easy to assess 
the level of physical discomfort, such as constipation, diarrhea, and thirst, more than hallucination or delirium. Assessments on a regular basis regarding physical discomfort prior to patients' complaints are required in clinical settings.

In the present study, verbal agitation was not significantly different according to gender, similar to the findings reported by Schreiner [9]. However, other studies have observed gender differences in verbal agitation in dementia patients, although the findings are contradictory. Kang [18] and Cohen-Mansfield and Libin [15] reported that women showed more verbal agitation them men, whereas Menon et al. [43] reported that men showed more verbal agitation. Thus, based on the literature it is difficult to draw a clear conclusion regarding the relationship between gender and verbal agitation in dementia patients. Replication research should be conducted with larger samples of dementia patients in various living arrangements (e.g., home and nursing homes). Once a sufficient number of studies have been conducted, a systematic literature review should be performed.

In previous studies, friendliness, marital relationship, and sociability before the occurrence of dementia were found to affect verbal agitation [13] [15] [18], but they were not in the present study. Few, if any, studies measured friendliness, marital relationship, and sociability in dementia patients in Korea, and the relationship between these characteristics and dementia has rarely been studied. Future research should investigate friendliness or sociability of patients before the occurrence of dementia and identify the relationship with verbal agitation. In addition, an intervention to prevent verbal agitation by increasing sociability will be needed.

Over $40 \%$ of dementia patients in Korea manifest verbal agitation such as screaming, cursing, and repetitive questioning [11]. In consideration of the fact that verbal agitation increases stress in caregivers as well as patients themselves, drug use in patients, and medical costs, identifying, preventing and managing the factors affecting verbal agitation is imperative in improving the quality of life in dementia patients and caregivers. The present study is of significance in that it is the first study which examined causes of verbal agitation in dementia patients living in nursing homes in Korea. The present study findings will provide basic evidence useful in the exploration of ways to prevent and manage verbal agitation in the study population.

\section{Conclusion}

This study was conducted with dementia patients living in nursing homes located in an area, and so there is a limitation in generalizing the findings. The findings of this study regarding gender, friendliness, and depression are not in accordance with those of studies conducted outside of Korea. Thus, a replication study should be conducted with a larger sample to examine causes of the inconsistencies. Lastly, it is suggested that caregivers systemically manage hallucination, physiological discomfort, and pain in dementia patients to reduce verbal 
agitation.

\section{Conflicts of Interest and Source of Funding}

This research was supported by Basic Science Research Program through the National Research Foundation of Korea (NRF) funded by Ministry of Education (No. 2017R1D1A3B03032896).

\section{References}

[1] Statistics Korea (2016) 2015 Elderly People Statistics. http://kosis.kr/index/index.do

[2] John, A.F., Korten, A.E. and Henderson, A.S. (1987) The Prevalence of Dementia: A Quantitative Integration of the Literature. Acta Psychiatrica Scandinavica, 76, 465-479. https://doi.org/10.1111/j.1600-0447.1987.tb02906.x

[3] National Institution of Health (2003) Progress Report on Alzheimer's Disease, USA.

[4] Ministry of Health \& Welfare (2012) National Dementia Strategy 2013-2015. http://www.silverweb.or.kr/_data/board_list_file/1/2012/1207301339541.pdf

[5] Kong, E.H., Evans, L.K. and Guevara, J.P. (2009) Nonpharmacological Intervention for Agitation in Dementia: A Systematic Review and Meta-Analysis. Aging \& Mental health, 13, 512-520. https://doi.org/10.1080/13607860902774394

[6] Kong, E.H. and Park, M. (2015) Effects of Music Therapy on Agitation in Dementia: Systematic Review and Meta-Analysis. Korean Journal of Adult Nursing, 27, 106-116. https://doi.org/10.7475/kjan.2015.27.1.106

[7] Cohen-Mansfield, J. and Billig, N. (1986) Agitated Behaviors in the Elderly: I. A Conceptual Review. Journal of the American Geriatrics Society, 34, 711-721. https://doi.org/10.1111/j.1532-5415.1986.tb04302.x

[8] Cohen-Mansfield, J. (2008) Agitated Behavior in Persons with Dementia: The Relationship between Type of Behavior, its Frequency, and Its Disruptiveness. Journal of Psychiatric Research, 43, 64-69. https://doi.org/10.1016/j.jpsychires.2008.02.003

[9] Schreiner, A.S. (2001) Aggressive Behaviors among Demented Nursing Home Residents in Japan. International Journal of Geriatric Psychiatry, 16, 209-215. https://doi.org/10.1002/1099-1166(200102)16:2<209::AID-GPS314>3.0.CO;2-9

[10] Gang, M., Park, H. and Park, H. (2016) Factors Affecting Agitation in Nursing Home Patients with Dementia. Journal of Korean Gerontological Nursing, 18, 41-52. https://doi.org/10.17079/jkgn.2016.18.1.41

[11] Kim, K.A. (2003) Development of an Assessment Tool of Problematic Behaviors for Institutionalized Old People with Dementia. Unpublished Doctor's Thesis, Seoul University, Seoul.

[12] Kong, E.H. (2005) Agitation in Dementia: Concept Clarification. Journal of Advanced Nursing, 52, 526-536. https://doi.org/10.1111/j.1365-2648.2005.03613.x

[13] Cohen-Mansfield, J., Marx, M.S. and Werner, P. (1992) Agitation in Elderly Persons: An Integrative Report of Findings in a Nursing Home. International Psychogeriatrics, 4, 221-240. https://doi.org/10.1017/S1041610292001285

[14] Cohen-Mansfield, J. and Marx, M.S. (1992) The Social Network of the Agitated Nursing Home Resident. Research on Aging, 14, 110-123. https://doi.org/10.1177/0164027592141006

[15] Cohen-Mansfield, J. and Libin, A. (2005) Verbal and Physical Non-Aggressive Agitated Behaviors in Elderly Persons with Dementia: Robustness of Syndromes. Jour- 
nal of Psychiatric Research, 39, 325-332. https://doi.org/10.1016/j.jpsychires.2004.08.009

[16] Pelletier, I.C. and Landreville, P. (2007) Discomfort and Agitation in Older Adults with Dementia. BMC Geriatrics, 7, 27. https://doi.org/10.1186/1471-2318-7-27

[17] Zuidema, S.U., de Jonghe, J.F., Verhey, F.R. and Koopmans, R.T. (2009) Predictors of Neuropsychiatric Symptoms in Nursing Home Patients: Influence of Gender and Dementia Severity. International Journal of Geriatric Psychiatry, 24, 1079-1086. https://doi.org/10.1002/gps.2225

[18] Kang, Y.S. (2000) A Study on Disturbing Behaviors of Demented Elderly Staying at Home. Journal of Korean Community Nursing, 11, 453-469.

[19] Algase, D.L., Beck, C., Kolanowski, A., Whall, A., Berent, S., Richards, K. and Beattie, E. (1996) Need-Driven Dementia-Compromised Behavior: An Alternative View of Disruptive Behavior. American Journal of Alzheimer's Disease, 11, 10-19. https://doi.org/10.1177/153331759601100603

[20] Suh, G.H. (2004) Agitated Behaviours among the Institutionalized Elderly with Dementia: Validation of the Korean Version of the Cohen-Mansfield Agitation Inventory. International Journal of Geriatric Psychiatry, 19, 378-385. https://doi.org/10.1002/gps.1097

[21] Kang, Y.W., Na, D.L. and Hahn, S.H. (1997) A Validity Study on the Korean Mini-Mental State Examination (K-MMSE) in Dementia Patients. Journal of the Korean Neurological Association, 15, 300-308.

[22] Folstein, M.F., Folstein, S.E. and McHugh, P.R. (1975) Mini-Mental State: A Practical Method for Grading the Cognitive State of Patients for the Clinician. Journal Psychiatry Research, 12, 189-198. https://doi.org/10.1016/0022-3956(75)90026-6

[23] Holden, U.P. and Sinebruchow, A. (1978) Reality Orientation Therapy: A Study Investigating the Value of this Therapy in the Rehabilitation of Elderly People. Age and Ageing, 7, 83-90. https://doi.org/10.1093/ageing/7.2.83

[24] Gang, M.H. (2005) Effects of Horticultural Intervention Program on Cognition, Emotion, Communication and Problematic Behavior in Older Adults with Alzheimer. Unpublished Doctor's Thesis, Chungnam National University, Daejeon.

[25] Won, C.W., Yang, K.Y., Rho, Y.G., Kim, S.Y., Lee, E.J., Yoon, J.L., et al. (2002) The Development of Korean Activities of Daily Living (K-ADL) and Korean Instrumental Activities of Daily Living (K-IADL) Scale. Journal of the Korean Geriatrics Society, 6, 107-120.

[26] Hurley, A.C., Volicer, B.J., Hanrahan, P.A., Houde, S. and Volicer, L. (1992) Assessment of Discomfort in Advanced Alzheimer Patients. Research in Nursing \& Health, 15, 369-377. https://doi.org/10.1002/nur.4770150506

[27] Kim, S.J. (2006) A Study on Pain-Causing Factors for the Dementia Suffering with Aged Women. Unpublished Master's Thesis, Chung-Ang University, Seoul.

[28] Alexopoulos, G.S., Abrams, R.C., Young, R.C. and Shamoian, C.A. (1988) Cornell Scale for Depression in Dementia. Biological Psychiatry, 23, 271-284. https://doi.org/10.1016/0006-3223(88)90038-8

[29] Kim, K.U. (2005) Dementia Care Assessment Packet. The Korean Association for Dementia, Seoul.

[30] Cummings, J.L., Mega, M., Gray, K., Rosenberg-Thompson, S., Carusi, D.A. and Gornbein, J. (1994) The Neuropsychiatric Inventory Comprehensive Assessment of Psychopathology in Dementia. Neurology, 44, 2308-2308.

https://doi.org/10.1212/WNL.44.12.2308 
[31] Choi, S.H., Na, D.L., Kwon, H.M., Yoon, S.J., Jeong, J.H. and Ha, C.K. (2000) The Korean Version of the Neuropsychiatric Inventory: A Scoring Tool for Neuropsychiatric Disturbance in Dementia Patients. Journal of Korean Medical Science, 15, 609-615. https://doi.org/10.3346/jkms.2000.15.6.609

[32] Buffum, M.D., Miaskowski, C., Sands, L. and Brod, M. (2001) A Pilot Study of the Relationship between Discomfort and Agitation in Patients with Dementia. Geriatric Nursing, 22, 80-85. https://doi.org/10.1067/mgn.2001.115196

[33] Talerico, K.A., Evans, L.K. and Strumpf, N.E. (2002) Mental Health Correlates of Aggression in Nursing Home Residents with Dementia. The Gerontologist, 42, 169-177. https://doi.org/10.1093/geront/42.2.169

[34] Cohen-Mansfield, J., Werner, P., Watson, V. and Pasis, S. (1995) Agitation among Elderly Persons at Adult Day-Care Centers: The Experiences of Relatives and Staff Members. International Psychogeriatrics, 7, 447-458. https://doi.org/10.1017/S1041610295002195

[35] Leonard, R., Tinetti, M.E., Allore, H.G. and Drickamer, M.A. (2006) Potentially Modifiable Resident Characteristics That Are Associated with Physical or Verbal Aggression among Nursing Home Residents with Dementia. Archives of Internal Medicine, 166, 1295-1300. https://doi.org/10.1001/archinte.166.12.1295

[36] Volicer, L., Frijters, D.H. and Van der Steen, J.T. (2012) Relationship between Symptoms of Depression and Agitation in Nursing Home Residents with Dementia. International Journal of Geriatric Psychiatry, 27, 749-754. https://doi.org/10.1002/gps.2800

[37] Hahn, S.J. and Paik, N.J. (2015) Pharmacological Treatment of Dementia. Brain \& Neurorehabilitation, 8, 19-23. https://doi.org/10.12786/bn.2015.8.1.19

[38] Kunik, M.E., Snow, A.L., Davila, J.A., Steele, A.B., Balasubramanyam, V., Doody, R.S., et al. (2010) Causes of Aggressive Behavior in Patients with Dementia. The Journal of Clinical Psychiatry, 71, 1145-1152. https://doi.org/10.4088/JCP.08m04703oli

[39] Chang, S.O. (2007) Development and Effect of Pain Management Protocol for Nursing Home Patients with Dementia. Journal of Korean Academy of Fundamentals of Nursing, 14, 29-43.

[40] Kim, S.J., Ryoo, E.N. and Park, K.S. (2007) A Study on Pain, Physical Function, Cognitive Function, Depression and Agitation in Elderly Women with Dementia. Journal of Korean Academy of Adult Nursing, 19, 401-412.

[41] Cohen-Mansfield, J. and Creedon, M. (2002) Nursing Staff Members' Perceptions of Pain Indicators in Persons with Severe Dementia. The Clinical Journal of Pain, 18, 64-73. https://doi.org/10.1097/00002508-200201000-00010

[42] Kim, E.J. (2006) Nurses' Attitudes and Perceptions of Pain in Patients with Severe Dementia. Clinical Nursing Research, 12, 159-167.

[43] Menon, A.S., Gruber-Baldini, A.L., Hebel, J.R., Kaup, B., Loreck, D., Itkin Zimmerman, S., et al. (2001) Relationship between Aggressive Behaviors and Depression among Nursing Home Residents with Dementia. International Journal of Geriatric Psychiatry, 16, 139-146.

https://doi.org/10.1002/1099-1166(200102)16:2<139::AID-GPS284>3.0.CO;2-5 